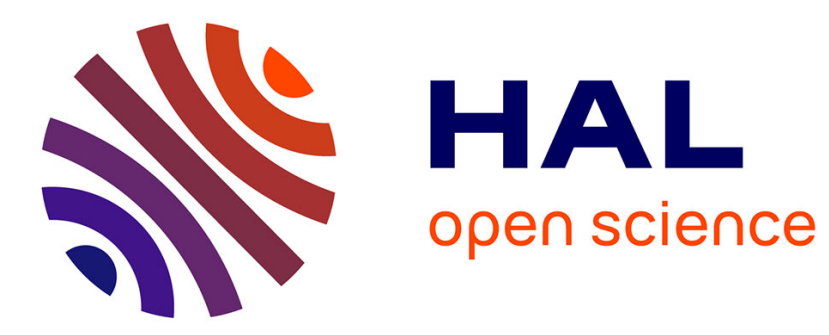

\title{
Laser-Induced Chemical Vapour Deposition of Silicon Carbonitride
}

W. Besling, P. van Der Put, J. Schoonman

\section{To cite this version:}

W. Besling, P. van Der Put, J. Schoonman. Laser-Induced Chemical Vapour Deposition of Silicon Carbonitride. Journal de Physique IV Proceedings, 1995, 05 (C5), pp.C5-953-C5-960. 10.1051/jphyscol:19955112 . jpa-00253781

\section{HAL Id: jpa-00253781 https://hal.science/jpa-00253781}

Submitted on 1 Jan 1995

HAL is a multi-disciplinary open access archive for the deposit and dissemination of scientific research documents, whether they are published or not. The documents may come from teaching and research institutions in France or abroad, or from public or private research centers.
L'archive ouverte pluridisciplinaire HAL, est destinée au dépôt et à la diffusion de documents scientifiques de niveau recherche, publiés ou non, émanant des établissements d'enseignement et de recherche français ou étrangers, des laboratoires publics ou privés. 
JOURNAL DE PHYSIQUE IV

Colloque C5, supplément au Journal de Physique II, Volume 5, juin 1995

\title{
Laser-Induced Chemical Vapour Deposition of Silicon Carbonitride
}

\author{
W.F.A. Besling, P.J.J.M. van der Put and J. Schoonman
}

Laboratory for Applied Inorganic Chemistry, Delft University of Technology, Julianalaan 136, 2628 BL Delft, The Netherlands

\begin{abstract}
Laser-induced Chemical Vapour Deposition of silicon carbonitride coatings and powders has been investigated using hexamethyldisilazane (HMDS) and ammonia as reactants. An industrial $\mathrm{CW} \mathrm{CO}_{2}$-laser in parallel configuration has been used to heat up the reactant gases. HMDS dissociates in the laser beam and reactive radicals are formed which increase rapidly in molecular weight by an addition mechanism. Dense polymer-like silicon carbonitride thin films and nanosized powders are formed depending on process conditions. Powder particles are deposited on a substrate by means of a thermal gradient. The primary particle size is about $30 \mathrm{~nm}$. The particles are agglomerated.

Depositions are characterized with spectroscopic and chemical analysis and correlated to some important laser process parameters. The powder deposit and the thin film consist of $\mathrm{Si}-\mathrm{N}, \mathrm{Si}-\mathrm{C}$ and Si-O bonds according to FTIR-spectroscopy and X-ray Photo-Electron Spectroscopy. A residual amount of hydrogen is present. The material is amorphous (XRD) and has a polymer-like structure. The overall composition varies around $\mathrm{Si}_{0.4} \mathrm{C}_{0.1} \mathrm{~N}_{0.3} \mathrm{O}_{0.2}$. The nitrogen content increases significantly by adding ammonia to the reactant gas flow. The high amount of oxygen is caused by hydrolysis and is a result of being exposed to air.
\end{abstract}

\section{INTRODUCTION}

Nanostructured ceramic and metallic materials show improved or even new properties compared to micro- or macrostructured materials. For example nanostructured ceramic/ceramic composites find increasing applications because of their remarkable mechanical properties and their oxidation resistance to high temperatures [1,2]. A very promising route for the production of these new materials is the synthesis of nanosized particles from the gas phase using a $\mathrm{CO}_{2}$-laser. With laser heated processes nanoparticles can be synthesized which are very pure and uniform in composition and particle size [3,4]. Synthesis of ultrafine $\mathrm{Si}, \mathrm{SiC}, \mathrm{Si}_{3} \mathrm{~N}_{4}$ and $\mathrm{SiC}_{\mathrm{x}} \mathrm{N}_{\mathrm{y}}$ particles have been reported already [3-6]. Also fine amorphous $\mathrm{Si} / \mathrm{C} / \mathrm{N}$ powders have been obtained from laser vapour phase reaction of organosilicon compounds [7-11].

Silicon carbide and silicon nitride are well known as wear resistant materials for cutting tools or inserts. Their resistance to high temperatures and corrosive atmospheres as well as other excellent properties, make them attractive materials for an even larger field of applications. CVD silicon nitride is used in passivation layers and diffusion barriers as well. Silicon carbide thin films have received considerable interest due to their promising applications as a variable bandgap material in semiconductor technology $[12,13]$. In order to combine the excellent characteristics of silicon nitride and silicon carbide, research is done at multicomponent materials based on silicon, carbon and nitrogen. Although SiCN deposits were previously obtained at elevated temperatures [1,1b], only few experiments have been carried out at low substrate temperatures [12,13]. A low deposition temperature is desirable for practical applications in electronic devices and protective coatings. 
Silane is widely used as main reactant in silicon technology. This gas however, is very hazardous and therefore not very attractive for large scale applications. Metalorganic precursors facilitate the synthesis of nanomaterials containing phases of desired composition and crystal structure [7-11]. Metalorganic precursors are particularly attractive since (1) reaction takes place at low temperature, (2) their volality is high, (3) phases with selected stoichiometry can be obtained and (4) some of them can absorb $\mathrm{CO}_{2}$-laser radiation.

This paper reports on the laser Chemical Vapour Deposition of silicon carbonitride powders and coatings using a metalorganic precursor, hexamethyldisilazane (HMDS), and ammonia as reactants. We present a new deposition technique in which laser activation is used, for preparing at low temperatures a uniform dispersion of the reinforcing phase when codepositing the ceramic matrix.

\subsection{General process description}

In the laser CVD process the laser beam is directed parallel to the substrate and intersects the gas flow perpendicularly (figure 1). The laser beam excites the reactant gas only and there is no interaction with the substrate. The gas molecules are directly heated by absorption of laser light in the laser beam. The substrate is positioned above the nozzle in order to make use of heat convection. Nanosized particles or thin films are formed depending on process conditions.

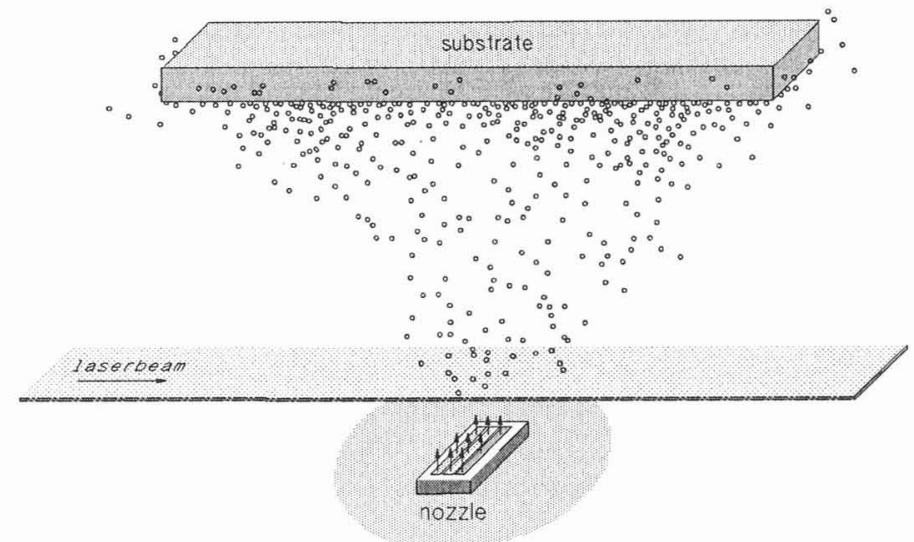

Figure 1: $\quad$ The laser PPCVD process

The purpose was to synthesize an aerosol of very fine ceramic particles, homogeneously nucleated from the gas phase by $\mathrm{CO}_{2}$-laser radiation. The particles are deposited on a substrate as a result of a temperature gradient (thermophoresis) [14]. The porous powder deposit can be densified by a simultaneous and heterogeneous CVD reaction [15]. In this way it is possible to deposit layers with controlled porosity at high deposition rates and at low substrate temperatures. This technique is called Laser Particle Precipitation-aided Chemical Vapor Deposition (Laser PPCVD).

The idea behind the use of a laser in the PPCVD process is totally new. In a laser beam very pure, nanosized and ideally shaped particles are formed. Laser synthesis of powders enables us to control the nucleation rate, particle growth, morfology and size. Particle deposition can be regulated easily because there is a natural temperature gradient between the hot reaction zone in the laser beam and the cooler substrate. In general particle deposition will result in an agglomerated powder deposit, which has a poor mechanical stability as a layer. In order to obtain a coherent layer the powder deposit should be sintered or a heterogeneous reaction should occur in order to interconnect the individual particles. The heterogeneous surface reaction can be controlled independently from the gas phase reactions in the laser PPCVD process in order to interconnect the powder deposit. This laser PPCVD technique of making layers with controlled porosity offers a variety of applications, e.g. thin, ceramic porous layers can be used as a catalyst carrier, a membrane or a porous electrode. 


\section{EXPERIMENTAL PROCEDURE}

A schematic representation of the reactor configuration is given in figure 1 . A $150 \mathrm{~W}$ industrial untuned continuous wave $\mathrm{CO}_{2}$-laser (Electrox) emitting at a wavelength of $\lambda=10.6 \mu \mathrm{m}$, is used to heat the reactants. The laser beam is focused in a flat plane $(0.6 \mathrm{~mm} \mathrm{x} 2 \mathrm{~cm})$ by a $\mathrm{ZnSe}$ lens. The intensity of the focused beam above the nozzle is $1080 \mathrm{~W} / \mathrm{cm}^{2}$. Reactor pressures are in the range from $100 \mathrm{mbar}$ to $500 \mathrm{mbar}$. The temperature of the substrate is kept at $150-200{ }^{\circ} \mathrm{C}$. The reactant purities are $99 \%$ hexamethyldisilazane (Aldrich) and $99.9 \%$ ammonia (Air products). Argon $99.9 \%$ (Air Products) is used as carrier gas for the HMDS vapour $\left(\mathrm{T}_{\text {evap }}=60^{\circ} \mathrm{C}\right)$. A protective nitrogen flow is used to prevent powder buildup on the $\mathrm{ZnSe}$ windows. Argon and nitrogen are purified using oxygen and water filters.

\subsection{Analytical methods}

The powder deposits and the thin films were characterized with spectroscopic and analytical methods. The morphology and size of the particles in the powder deposit were studied with transmission electron microscopy (TEM, Philips EM400 and Philips CM30). Scanning electron microscopy (SEM, JEOL JSM-35) was used to obtain the film thickness and to study the morphology of the deposited layers. Chemical composition is determined with semi-quantitative energy dispersive X-ray analysis (EDX, Link-ISIS Oxford Instruments Ltd., connected to a JEOL JSM-35 SEM) at an accelerating voltage of $20 \mathrm{keV}$. Information about chemical bonding and composition is obtained from X-ray Photo-electron Spectroscopy (XPS, Perkin Elmer PHI 5400 ESCA system). Quantitative analysis (multiplex spectra) has been performed by means of the following elemental sensitivity factors: $\mathrm{Si}=0.339, \mathrm{C}=0.296, \mathrm{~N}=0.477, \mathrm{O}=0.711$ (data from $\mathrm{PHI}$ ). A depth profile has been made by sputtering the deposits with $3.5 \mathrm{kV} \mathrm{Ar}{ }^{+}$-ions. The $\mathrm{Si}-K L_{23} L_{23}$ Auger line is created by the $\mathrm{Mg}-\mathrm{K} \alpha$ $\mathrm{X}$-ray line at $1253.6 \mathrm{eV}$. Chemical bonding in the powder is also investigated with Fourier Transform Infrared Spectroscopy (FTIR). The spectra are taken from $\mathrm{KBr}$ tablets. Possible crystalline phases are identified from X-ray diffraction (XRD) which have been recorded using a Philips PW 1840 automated diffractometer with a copper X-ray tube.

\section{RESULTS AND DISCUSSION}

\subsection{Process parameters}

The absorptivity for laser radiation depends on the partial pressure of the gas, temperature and the chosen $\mathrm{CO}_{2}$ laser line and is a strong function of total pressure. The absorptivity of the reactant mixture is an important parameter in the laser PPCVD process because it influences the temperature of the reactant mixture directly. Therefore, absorptivities were measured in the reactor set up. The results of these measurements show that $\mathrm{NH}_{3}$ acts as the main absorber for laser radiation when the concentration of HMDS is low. In this way the reactant mixture can be activated at very low HMDS concentration levels where homogeneous nucleation does not take place. At pressures below 100 mbar no reaction occurs due to little absorption resulting in a too low gas phase temperature necessary for reaction. Particles are formed in a flame when the reactor pressure exceeds 500 mbar. Under these conditions the deposits are loose. The structure becomes more dense by reducing the reactor pressure and by adding ammonia to the reactant gases. Reaction then occurs without a flame. An increase in ammonia partial pressure favours the incorporation of nitrogen in the deposits.

\subsection{Morphology and crystal structure}

The powder deposits are white and have a cauliflower structure (figure 2). The structure becomes more dense by changing the $\mathrm{HMDS} / \mathrm{NH}_{3}$ ratio. The primary particles are more or less spherical and have about the same diameter according to TEM-photographs (figure 3). The primary particles synthesized under ammonia, are $30 \pm 10 \mathrm{~nm}$ in diameter. The particles which are produced without ammonia, are $80 \pm 10 \mathrm{~nm}$ in size. The particles are agglomerated in clusters. The primary particle size becomes smaller when the reactant concentration is lower. 


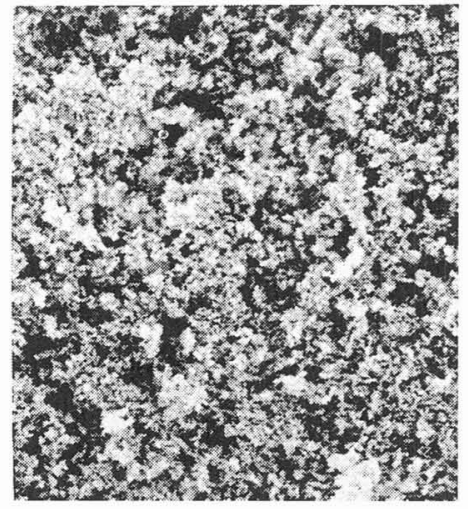

$20 \mu \mathrm{m}$

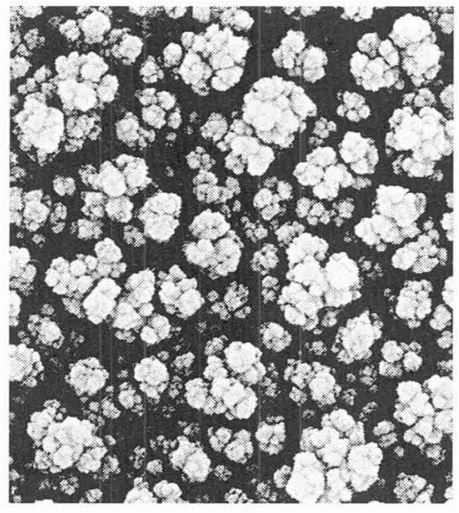

$20 \mu \mathrm{m}$

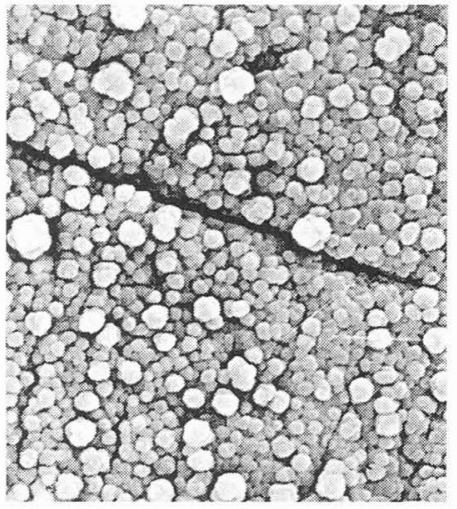

$20 \mu \mathrm{m}$

Figure 2: $\quad$ SEM photographs of highly porous to relatively dense powder deposits ( $35 \mathrm{kV})$.

According to $\mathrm{XRD}$, the powder deposit is amorphous and remains amorphous after heating in nitrogen atmosphere at $1460{ }^{\circ} \mathrm{C}$ for half an hour. The weight loss under these conditions is about 4\%. The weight loss in the TGA experiments is small compared to the $10 \%$ observed by others [10]. These results indicate a low hydrogenation level and are consistent with IR analysis which show no significant Si-H bonding at $2260 \mathrm{~cm}^{-1}$ and some $\mathrm{N}-\mathrm{H}$ bonding at $3350 \mathrm{~cm}^{-1}$. TGA experiments of laser pyrolyzed HMDS powders indicate that under $\mathrm{Ar}$ or $\mathrm{N}_{2}$ atmosphere the weight loss is correlated to $\mathrm{CH}_{4}$ release [11]. Crystallization occurs in these experiments at $1400-1500{ }^{\circ} \mathrm{C}$. The IRspectra after TGA no longer show hydrogenated structures such as $\mathrm{Si}-\mathrm{H}$ and $\mathrm{Si}-\mathrm{CH}_{3}$. Also in our samples the $\mathrm{Si}-\mathrm{CH}_{3}$ peak disappeared but remained $\mathrm{X}$-ray amorphous at these conditions.

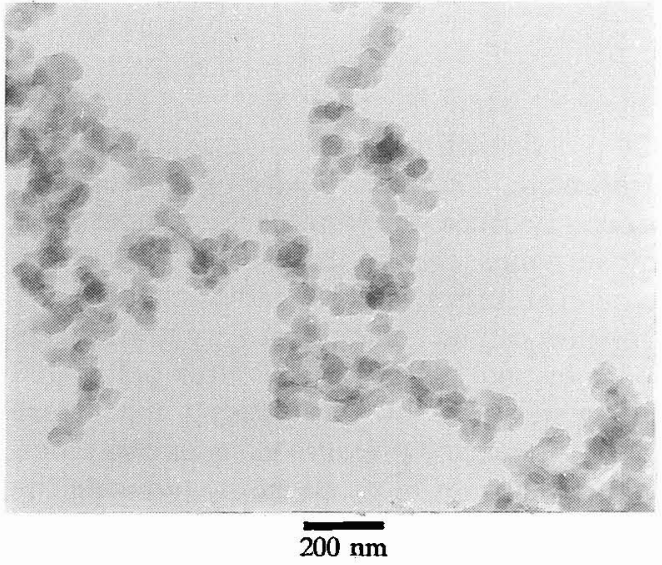

Figure 3: TEM photograph of powder synthesized with ammonia, primary particle size is $40 \mathrm{~nm}$, $\mathrm{p}_{\text {reactor }}=200$ mbar.

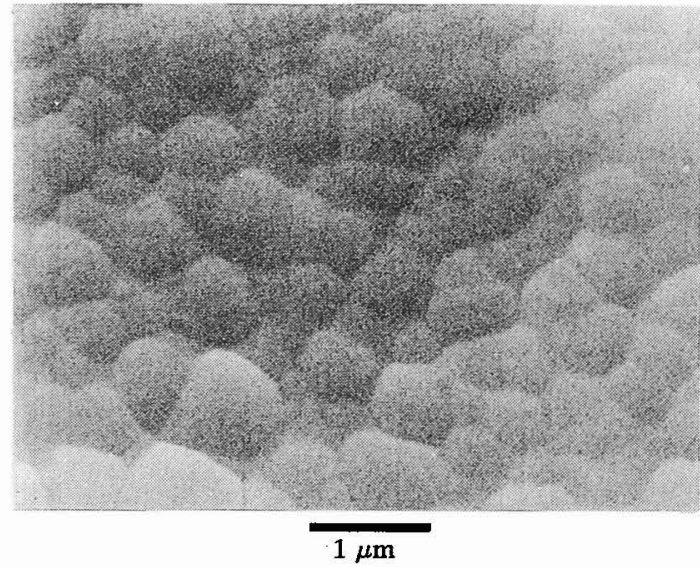

Figure 4: SEM photograph $(30 \mathrm{kV})$ of dense amorphous film synthesized with ammonia, $\mathrm{p}_{\text {reactor }}=200 \mathrm{mbar}$.

Dense, transparant and colourless films have been deposited on glass, silicon and copper and adhere very well to the underlying surface. The growth rate is large: $0.1 \mu \mathrm{m} / \mathrm{min}$. These thin films are highly oxidized on the outside and inside of the layer (according to a XPS depth profile) so we assumed that the thin film had a porous character but this was not detectable with SEM (figure 4). 


\subsection{Composition}

XPS analysis is performed on the white powder deposits and the thin transparant films. The N/Si ratio in the sputtered samples was found to be $0.5 \pm 0.1$ for the thin film and $0.9 \pm 0.1 \mathrm{eV}$ for the powder deposits. In stoichiometric silicon nitride this means an excess of silicon in the film. However, also the bonding of silicon to carbon and oxygen has to be taken into account. When the deposit is considered as a mixture of four stoichiometric compounds $\left(\mathrm{Si}_{3} \mathrm{~N}_{4}, \mathrm{SiC}, \mathrm{SiO}_{2}\right.$ and $\left.\mathrm{C}\right)$ it is found that this view-point is possible for the powder deposit (table 1). The thin film however, should consist of substoichiometric silicon nitride ( $\mathrm{SiN}_{\mathrm{y}}$ with $0<\mathrm{y}<1.33$ ). Here it is assumed that the concentration of free silicon and free carbon in the thin film is very low in view of the fact that the layer is transparant. Also XPS indicates that there is no free silicon present because of the fact that the $\mathrm{Si}_{2 \mathrm{p}}$ peak is positioned at $100.4 \pm 0.2 \mathrm{eV}\left(\mathrm{SiH}_{\mathrm{y}}: \mathrm{E}_{\mathrm{B}}=99.2 \mathrm{eV}\right)$. According to the $\mathrm{C}_{1 \mathrm{~s}}$ peak, two components are present: free carbon $\left(\mathrm{E}_{\mathrm{B}}=284.6 \mathrm{eV}\right)$ and carbon bonded to silicon $\left(\mathrm{E}_{\mathrm{B}}=282.5 \mathrm{eV}\right)$. The ratio between free carbon and $\mathrm{Si}-\mathrm{C}$ is $15 \%$ in the thin film and $40 \%$ in the powder deposit. These results are consistent with gas analysis of the powder (Ströhlein CS-Mat 650) which indicates a low free carbon concentration (4\%). The results are summarized in table 1.

Table 1; Analytical data of thin film and powder deposit synthesized at $\mathrm{p}_{\text {reactor }}=200 \mathrm{mbar}, \phi_{\mathrm{NH} 3}=4 \mathrm{ml} / \mathrm{min}: \mathrm{XPS}$ measurements of samples after $30 \mathrm{~min}$. sputtering with $3.5 \mathrm{kV} \mathrm{Ar}^{+}$. $\mathrm{y}$ is the stoichiometric factor of $\mathrm{SiN}_{\mathrm{y}}$.

\begin{tabular}{|c|c|c|c|c|c|c|c|c|c|c|}
\hline & $\begin{array}{l}\text { at } \% \\
\mathrm{Si}\end{array}$ & $\mathrm{C}$ & $\mathrm{N}$ & $\mathrm{O}$ & $\begin{array}{l}\text { at. ba } \\
\operatorname{SiN}_{\mathrm{y}}\end{array}$ & $\begin{array}{l}\text { lance } \\
\text { SiC }\end{array}$ & $\begin{array}{l}\text { nixture } \\
\mathrm{SiO}_{2} \\
\end{array}$ & $\mathrm{C}$ & $y$ & $\begin{array}{l}\text { f.w.h.m. } \\
\mathrm{Si}_{2 \mathrm{p}} \quad(\mathrm{eV})\end{array}$ \\
\hline powder & 39 & 8 & 34 & 19 & 25.5 & 4 & 9.5 & 4 & 1.33 & 3.2 \\
\hline thin film & 44 & 16 & 21 & 19 & 21 & 13.5 & 9.5 & 2.5 & 1.00 & 2.6 \\
\hline & & & & & 18.5 & 16 & 9.5 & - & 1.15 & \\
\hline
\end{tabular}

The oxygen contamination is mainly caused by hydrolysis and/or oxidation. The oxygen concentration in the deposits drops drastically (XPS measurements) when the top layers are removed by sputtering with $3.5 \mathrm{kV} \mathrm{Ar}^{+}$ions. The oxygen concentration is high, due to the large surface area of the nanosized particles. The particles in the inner porous structure are also exposed to air and covered with an oxide layer. This explains the high remaining oxygen content (longer sputtering would not reduce the oxygen content anymore). Also FTIR shows clearly that the amount of oxygen increases during exposure to air.

The carbon/nitrogen ratio in the deposits can be controlled easily by changing the HMDS/NH 3 ratio of the reactant gas flow. The nitrogen content increases significantly at the expense of carbon in the deposits when the $\mathrm{NH}_{3}$ flow is increased. These results were also found by Herlin et al. [11]. When HMDS vapour is introduced alone in the laser beam we obtain a $\mathrm{C} / \mathrm{N}$ ratio of 0.6 in the powder deposit. These results differ substantially from the results of Rice and Woodin [8] who synthesized a grey powder with formula $\mathrm{Si}_{2} \mathrm{~N}_{0.9} \mathrm{C}_{2.4} \mathrm{H}$ by pyrolyzing $\mathrm{HMDS}$ in a $\mathrm{CO}_{2}$-laser beam. They found best results at high laser flux $\left(480 \mathrm{~W} / \mathrm{cm}^{2}\right)$. We used a much higher power density $\left(1080 \mathrm{~W} / \mathrm{cm}^{2}\right)$ and a lower HMDS concentration in the argon flow resulting in a much larger conversion of the silazane precursor. It can be concluded that the chemical composition can be controlled easily by changing the HMDS/ $\mathrm{NH}_{3}$ ratio and thit powders with a high nitrogen content can be obtained by increasing the power density.

Suzuki et al. made a $\mathrm{Si}_{3} \mathrm{~N}_{4} / \mathrm{SiC}$ composite powder by irradiating a mixture of silane, ethene and ammonia with a $\mathrm{CO}_{2}$-laser [6]. The carbon and the nitrogen content can be varied between zero and 30 weight procent. Alexandrescu et al. [5] obtained comparable results by synthesizing crystalline $\mathrm{Si} / \mathrm{C} / \mathrm{N}$ powders with a $\mathrm{CO}_{2}$-laser from silane and mono- and dimethylamine. XPS analysis showed that all powders contained twice as much carbon than nitrogen (C: 15-28 at\% and N: 7-14 at\%) and had a high oxygen content (30-40 at \%). The silicon content varied between 30 and 40 at\%. The FTIR spectra showed a broad absorption band at 700 to $1200 \mathrm{~cm}^{-1}$. 


\subsection{Chemical bonding}

\subsubsection{FTIR}

The FTIR-spectra show a broad absorption band which is located at $950 \mathrm{~cm}^{-1}$. This peak has several shoulders which consist of overlapping Si-N, Si-C and Si-O peaks. The Si-N vibration is absorbing at $950 \mathrm{~cm}^{-1}$. The Si-C peak is located at $840 \mathrm{~cm}^{-1}$ but can not be distinguished from the Si-N peak. The Si-O absorption band is rather broad $\left(1050-1100 \mathrm{~cm}^{-1}\right)$ and is clearly present. The main peak at $950 \mathrm{~cm}^{-1}$ shifts to higher frequency when the powder is not analysed directly after deposition. This suggests that, being exposed to air, water vapour causes hydrolysis. It is well known that the Si-N bond is very sensitive for water and reacts at the surface to Si-OH. In the FTIR-spectra a small, broad peak appears between 450 and $500 \mathrm{~cm}^{-1}$. This peak could be from a Si-O $\left(470 \mathrm{~cm}^{-1}\right)$ or a Si-N absorption band $\left(450 \mathrm{~cm}^{-1}\right)$ or from a largely oxidized phase of the oxynitrides [5]. In a crystalline $\mathrm{Si}_{3} \mathrm{~N}_{4}$ reference sample however, two distinctive peaks can be noticed. In the spectra a small, sharp peak is visible at $1270 \mathrm{~cm}^{-1}$ belonging to the Si-CH bond $\left(1260 \mathrm{~cm}^{-1}\right)$ or more likely to Si-O surface bonds $\left(1280 \mathrm{~cm}^{-1}\right)$ [5]. A Si-H absorption band is neither perceptible at 2130 nor $656 \mathrm{~cm}^{-1}$.

All the characteristic absorption bands of HMDS are strongly reduced or have disappeared in the absorption spectrum of the product except the Si-N-Si bond at $940 \mathrm{~cm}^{-1}$. A minor absorption band at $3350 \mathrm{~cm}^{-1}$ indicates $\mathrm{N}-\mathrm{H}$ streching $\left(3330 \mathrm{~cm}^{-1}\right)$. The $\delta\left(\mathrm{Si}_{2} \mathrm{NH}\right)$ band at $1188 \mathrm{~cm}^{-1}$ however, is not visible anymore. The absorption band $\delta_{s}\left(\mathrm{CH}_{3}\right)$ of the methyl group at $1270 \mathrm{~cm}^{-1}$ has almost disappeared. The $\rho_{\text {as }}\left(\mathrm{CH}_{3}\right)$ at $840 \mathrm{~cm}^{-1}$ is diminished and not visible anymore as a separate peak. During laser pyrolysis the Si-N-Si bond remained intact but the methyl groups were removed to a great extent. These FTIR results show that the methyl groups were partially eliminated in the presence of ammonia probably resulting in the formation of active $-\mathrm{Si}-\mathrm{NH}_{2}$ functionalities. These reactive groups could start extensive crosslinking reactions resulting in highly branched structures [10].

\subsubsection{XPS analysis}

XPS analysis gives direct information about the bonding type and the geometry of the atoms in molecules. Chemical shifts in bonding energy of the photo-electron peaks occur when there is a change in the valence state of the bonding atoms. When the substrate is charged, the XPS-peaks will shift and broaden. The "chemical shift" will become less clear. Therefore it is difficult to discuss chemical bonding through chemical shift measurements. A correction for the shift caused by charging, is obtained from the shift in bonding energy of adventitious carbon $(284.6 \mathrm{eV})$.

All $\mathrm{N}_{1 \mathrm{~s}}$ XPS spectra were featureless single component Gaussian peaks centered around $397.8 \pm$ $0.2 \mathrm{eV}$. The $\mathrm{N}_{1 \mathrm{~s}}$ line position indicates that nitrogen is bonded to silicon only. There is no evidence that $\mathrm{C}-\mathrm{N}$ bonds are present despite the fact that the f.w.h.m. is rather broad $(2.8 \mathrm{eV})$. The carbon peak can be deconvoluted in two separate peaks: carbon bonded to silicon $\left(\mathrm{E}_{\mathrm{B}}=282.8 \mathrm{eV}\right)$ and free carbon $\left(E_{B}=284.6 \mathrm{eV}\right)$. Free carbon was also detected in the powder sample with gas analysis. The amount of free carbon is in agreement with $\mathrm{SiC} / \mathrm{C}$ ratio calculated from the deconvoluted $\mathrm{C}_{1 \mathrm{~s}}$ spectra. Ducarroir et al. [12] found much larger f.w.m.h. values and a clear peak asymmetry indicating the existence of C-N bonds. Oxygen is bonded to silicon only (f.w.h.m. $2.8 \mathrm{eV}$, line position $532.5 \mathrm{eV}$ ). This binding energy is rather low compared to the corresponding value of the $\mathrm{SiO}_{2}$ peak $(532.5-533.3 \mathrm{eV})$. According to Padmanabhan and Saha this could be due to nonstoichiometry in the oxide layer [16].

It follows from these results that silicon is bonded to nitrogen, carbon and oxygen. The $\mathrm{Si}_{2 \mathrm{p}}$ binding energy was found to be $100.4 \pm 0.2 \mathrm{eV}$. The $\mathrm{Si}_{2 \mathrm{p}}$ peak must be assigned to substoichiometric nitride $\operatorname{SiN}_{\mathrm{y}}(0<\mathrm{y}<1.00)$ [16] or to silicon-carbon bonds $\left(\mathrm{E}_{\mathrm{B}}=99.8-100.8 \mathrm{eV}\right)$. Free silicon is not present according to the $\mathrm{Si}_{2 \mathrm{p}}$ peak position $\left(\mathrm{SiH}_{\mathrm{y}}: \mathrm{E}_{\mathrm{B}}=99.2 \mathrm{eV}\right)$. Because of the fact that the nitrogen content is much higher than the carbon content, the main contribution is attributed to $\mathrm{SiN}_{\mathrm{y}}$ bonding (the $\mathrm{C} / \mathrm{N}$ ratio is 0.75 in the thin film and 0.25 in the powder deposit). This is also indicated by the difference $\Delta E$ in the positions of the $\mathrm{N}_{1 \mathrm{~s}}$ and the $\mathrm{Si}_{2 \mathrm{p}}$ peak. $\Delta E$ was found to be $297.4 \mathrm{eV}$ which is higher than the corresponding value of $296.3 \mathrm{eV}$ found in (near stoichiometric) photo CVD 
nitrides [16]. The full width at half maximum (f.w.h.m.) of the $\mathrm{Si}_{2 \mathrm{p}}$ is relatively small $(2.6 \mathrm{eV})$ compared to the much broader peak of the powder deposits $(3.2 \mathrm{eV})$. However, it was not possible to deconvolute the $\mathrm{Si}_{2 \mathrm{p}}$ peak into separate $\mathrm{Si}_{3} \mathrm{~N}_{4}, \mathrm{SiC}$ and $\mathrm{SiO}_{2}$ peaks in the right molar ratio and at the right relative position. Also Ducarroir et al. [12] found, referring to the $\mathrm{Si}_{2 \mathrm{p}}$ XPS peak, that it was impossible to relate the broadening with the presence of several kinds of bonding in the film. We think that the laser synthesized SiCN powders and coatings show a far more complicated chemical environment than a simple mixture situation of $\mathrm{Si}_{3} \mathrm{~N}_{4}, \mathrm{SiC}$, and $\mathrm{SiO}_{2}$ phases. Various bonding states are present where silicon is bonded to carbon, nitrogen and oxygen. This is not surprising considering the amorphous nature of the deposits.

The kinetic energy of $\mathrm{Si}_{\mathrm{KLL}}$ Auger electrons of $\mathrm{SiN}_{\mathrm{y}}, \mathrm{SiC}, \mathrm{Si}_{3} \mathrm{~N}_{4}$ and $\mathrm{SiO}_{2}$ is 1614.4, 1614, 1612.8 and $1610.4 \mathrm{eV}$ respectively [16,17]. The value for our deposit was found to be $1611.3 \mathrm{eV}$ for the thin film and $1610.1 \mathrm{eV}$ for the powder deposit. The $\mathrm{Si}_{\mathrm{KLL}}$ Auger line is outside the $\mathrm{Si}_{3} \mathrm{~N}_{4}$ and the $\mathrm{SiC}$ region. The Auger parameter, the difference in energy between the Auger electrons and the photo-electrons, is insensitive for charging and in some cases also more sensitive for changes in chemical bonding state than the photo-electron or the Auger shifts. The Augerparameter is very low (1710 eV) compared to values for silicon carbonitride $(1714.5 \pm 0.2 \mathrm{eV})$ found by Ducarroir et al. [12]. Our values are close to the Augerparameter of tetramethylsilane (TMS) and silicones but are not in the $\mathrm{SiN}_{\mathrm{y}}$ region [17]. This could also be an indication of the polymeric nature of the deposits. In table 2 the measured energies of the elements are summarized.

Table 2: $\quad$ Measured binding energy $\mathrm{E}_{\mathrm{B}}$, the kinetic energy of the $\mathrm{Si}_{\mathrm{KLL}}$ Auger electrons and the Augerparameter $\alpha$ of the powder deposits and thin films. The values are corrected to the binding energy of adventitious carbon $\left(\mathrm{E}_{\mathrm{B}}=284.6 \mathrm{eV}\right)$.

\begin{tabular}{|c|c|c|c|c|c|c|}
\hline \multirow[b]{2}{*}{$\begin{array}{l}\text { element } \\
\text { line }\end{array}$} & \multicolumn{2}{|c|}{ Powder deposit } & \multicolumn{2}{|c|}{ Thin film } & \multirow[b]{2}{*}{$\begin{array}{l}\text { bonding } \\
\text { type }\end{array}$} & \multirow[b]{2}{*}{$\begin{array}{l}\mathrm{E}_{\mathrm{B}} \text { literature }[17] \\
(\mathrm{eV})\end{array}$} \\
\hline & $\begin{array}{l}\mathrm{E}_{\mathrm{B}} \\
(\mathrm{eV})\end{array}$ & $\begin{array}{l}\text { f.w.h.m. } \\
(\mathrm{eV})\end{array}$ & $\begin{array}{l}E_{B} \\
(e V)\end{array}$ & $\begin{array}{l}\text { f.w.h.m. } \\
(\mathrm{eV})\end{array}$ & & \\
\hline $\mathrm{Si}_{2 \mathrm{p}}$ & 100.4 & 3.2 & 100.4 & 2.6 & $\begin{array}{l}\mathrm{Si}-\mathrm{C} \\
\mathrm{SiN}_{\mathrm{y}} \\
\mathrm{Si}_{3} \mathrm{~N}_{4} \\
\mathrm{Si}-\mathrm{O}\end{array}$ & $\begin{aligned} 99.8 & -100.8 \\
100.2 & -100.6 \\
101.5 & -102.3 \\
102 & -103\end{aligned}$ \\
\hline $\mathrm{C}_{1 \mathrm{~s}}$ & 283.8 & 4.0 & 282.3 & 2.8 & carbide & $280.7-283$ \\
\hline $\mathrm{C}_{1 \mathrm{~s}}$ deconvoluted & 282.9 & 2.9 & 282.3 & 2.5 & $\mathrm{Si}-\mathrm{C}$ & 282.5 \\
\hline & 284.6 & 3.1 & 284.6 & 2.0 & free carbon & 284.6 \\
\hline $\mathrm{N}_{1 \mathrm{~s}}$ & 397.8 & 2.8 & 397.8 & 2.1 & Si-N & $397.1-397.8$ \\
\hline $\mathrm{O}_{1 \mathrm{~s}}$ & 532.5 & 2.8 & 532.5 & 2.1 & $\mathrm{SiO}_{2}$ & $532.5-533.3$ \\
\hline $\mathbf{E}_{\mathrm{K}}\left(\mathrm{Si}_{\mathrm{KLl}}\right.$ Auger $)$ & 1610.1 & 4.4 & 1611.3 & 3.8 & Si-O, TMS & $1609-1610$ \\
\hline Augerparameter & 1710.5 & & 1711.7 & & silicone, TMS & 1712,1710 \\
\hline
\end{tabular}

Suzuki et al. report a difference in bonding state between a powder mixture of $\mathrm{SiC}$ with $\mathrm{Si}_{3} \mathrm{~N}_{4}$ and a laser synthesized $\mathrm{Si}_{3} \mathrm{~N}_{4} / \mathrm{SiC}$ composite powder [6]. The $\mathrm{Si}_{2}$-spectra of the mixed powders consist of separate $\mathrm{SiC}$ and $\mathrm{Si}_{3} \mathrm{~N}_{4}$ peaks. The $\mathrm{Si}_{2 \mathrm{p}}$-peak of the $\mathrm{Si}_{3} \mathrm{~N}_{4} / \mathrm{SiC}$ composite is just one peak with a bonding energy of $101.3 \mathrm{eV}$ indicating $\mathrm{Sl}_{3} \mathrm{~N}_{4}$ bonds. However, the XRD diffraction pattern of this composite powder shows only a broad SiC-peak. The fact that the $\mathrm{Si}_{2 \mathrm{p}}$-peak hardly shows a second peak or even a shoulder at the bonding energy of $\mathrm{SiC}$, indicates a totally different bonding state in the composite powder. However, our XPS-spectra differ from these spectra. The chemical environment around silicon does not resemble a $\mathrm{Si}_{3} \mathrm{~N}_{4}, \mathrm{SiC}$ or $\mathrm{SiO}_{2}$ phase. It is more like a polymer where silicon is surrounded and bounded to nitrogen, carbon and oxygen. This is especially the case for the thin film where the f.w.h.m. is small $(2.6 \mathrm{eV})$. In the powder deposit two different phases can be present because the f.w.h.m. is much larger $(3.2 \mathrm{eV})$. XPS shows that the deposits consist of a crosslinked polymer-like structure with $\mathrm{C}$-Si-N bonds with a characteristic $\mathrm{Si}_{2 \mathrm{p}}$ bonding energy of $100.4 \mathrm{eV}$. 


\section{CONCLUSION}

Silicon carbonitride ultrafine particles and thin films were synthesized by laser-induced Chemical Vapor Deposition (LICVD) using hexamethyldisilazane (HMDS) and ammonia as reactants. The composition of the powder deposits and the thin films could be controlled by changing the reactor pressure and the $\mathrm{HMDS} / \mathrm{NH}_{3}$ flow rate and ratio.

The results of the XPS measurements showed that the silicon carbonitride is not a composite mixture of $\mathrm{SiC}$ and $\mathrm{Si}_{3} \mathrm{~N}_{4}$ phases but heavily cross-linked polymer with $\mathrm{C}-\mathrm{Si}-\mathrm{N}$ chemical bonds. This follows from the position and shape of one $\mathrm{Si}_{2 \mathrm{p}}$ peak in the XPS-spectra at $100.4 \mathrm{eV}$ in combination with an extreme low Auger parameter (1710.5 eV). More than one bond (for example a Si-C and $\mathrm{Si}-\mathrm{N}$ bond) will result in two distinctive peaks in the XPS-spectrum or will at least lead to peakbroadening or a clear asymmetry will be visible. Furthermore, the position of the $\mathrm{N}_{1 \mathrm{~s}}$-peak indicates that nitrogen is bonded to silicon and not to carbon, the shape and position of the $\mathrm{C}_{1 \mathrm{~s}}-$ peak denotes the existance of carbon-silicon bonds and free carbon (peak asymmetry).

The obtained microstructure of the deposits depends on the particle deposition rate, sintering and heterogeneous reaction at the surface. Particle deposition can be regulated easily because there is a natural temperature gradient between the hot reaction zone in the laser beam and the cooler substrate. The heterogeneous surface reaction can be controlled independantly from the gas phase reactions in the laser PPCVD process in order to interconnect the powder deposit. In this way it is possible to deposit layers with controlled porosity at high deposition rates and low substrate temperatures. Laser PPCVD provides an excellent control over the particle deposition rate and the growth rate of the second phase.

\section{References}

[1] Lackey W.J., Smith A.W., Dillard D.M., Twait D.J., Codeposition of dispersed phase ceramic composites, Proc. of the Tenth Int. Conf. on CVD, Cullen G.W. and Blocher J.M. Jr. Eds, (The Electrochemical Society, Pennington, N.J., 1987) pp. 1008-1027.

[1b ] Goto T. and Hirai T., J. Mater. Sci., 16 (1981) 17; 16 (1981) 2877.

[2] Clarke D.R., J. Am. Ceram. Soc., 75 [4] (1992) 739-759.

[3] Cannon W.R., Danforth S.C., Flint J.H., Haggerty J.S., Marra R.A., J. Am. Cer. Soc., 65[7] (1982) 324-330.

[4] Cannon W.R., Danforth S.C., Haggerty J.S., Marra R.A., J. Am. Cer. Soc., 65[7] (1982) 330-335.

[5] Alexandrescu R., Morjan I., Borsella E., Botti S. and Fantoni R., J. Mater. Sci., 6[11] (1991) 2442-2451.

[6] Suzuki M., Maniette Y., Nakata Y. and Okutani T., J. Am. Ceram. Soc., 76[5] (1993) 1195-1200.

[7] Rice G.W. and Woodin R.L., J. Mater. Res., 4 [6] (1989) 1538-1548.

[8] Magee A.P., Strutt P.R., and Gonsalves K.E., Chem. Mater., 2 (1990) 232-235.

[9] Xiao T.D., Strutt P.R., and Gonsalves K.E., Mat. Res. Soc. Symp. Proc., 168, Materials Research Society, (1990)

[10] Gonsalves K.E., Strutt P.R., Xiao T.D., and Klemens P.G., J. Mater. Sci, 27 (1992) 3231-3238.

[11] Herlin N., Luce M., Musset E., and Cauchetier M., J. Eur. Cer. Soc., 13 (1994) 285-291.

[12] Ducarroir M., Zhang W., and Berjoan R., Journal de Physique $I V$, Colloque C3, supplément au Journal de Physique II, 3 (1993) 247-254.

[13] Zhang W., Zhang K. and Wang B., Mat. Sci. Eng., B26 (1994) 133-140.

[14] Komiyama H., Osawa T., Shimogaki Y., Wakita N., Minamiyama M. and Ueoka T., Particle Precipitation Aided Chemical Vapour Deposition for rapid growth of ceramic films, Proc. of the Tenth Int. Conf. on CVD, Cullen G.W. and Blocher J.M. Jr. Eds, (The Electrochemical Society, 1987) pp. 1119-1127.

[15] Dekker J.P., CVD Techniques for the synthesis and modification of porous ceramics, (PhD Thesis, TU-Delft, 1994) pp. 125-145.

[16] Padmanabhan R. and Saha N.C., J. Vac. Sci. Technol. A, 6 [4] (1988) 2226-2231.

[17] Moulder J.F., Stickle W.F. et al., Handbook of X-ray Photoelectron Spectroscopy, (Perkin Elmer Corp., Minnesota, USA, 1992). 